\title{
Determining the climatologically suitable areas for wheat production using MODIS-NDVI in Mashhad, Iran
}

\author{
S. H. Sanaeinejad, S. M. Hasheminiya \& S. Khojasteh \\ Water Engr. Dept., Ferdowsi University of Mashhad, Iran
}

\begin{abstract}
One of the most important factors in sustainable irrigation is the adaptability of crops to climate. Vegetative vigor or "greenness" of wheat could be considered as an appropriate index to measure water availability and deficiency stress and also plant health, plant density and quality. The index is called Normalized Difference Vegetation Index (NDVI). In this study MODIS-NDVI values were compared with climatological parameters to assess the relations between vegetative vigor and climatological parameters. The NDVI values for three selected wheat farms in Mashhad area were calculated using MODIS images for 2003 and 2004 growing seasons. The data of four climatological parameters including air temperature, precipitation, relative humidity and sunshine hours were also collected from the nearest weather stations. Then a multi-regression statistical analysis was performed to find the relation between wheat NDVI and climatological parameters in the study area. Pertaining statistical methods including Mixed, and Stepwise (Forward and Backward) were used in the analysis. Scattering matrix was used to determine the data scattering of the models and NDVI values for comparison. The results showed that backward method was more appropriate than the other two methods for predicting NDVI values of the study area. After finalizing this model the results were statistically tested using $20 \%$ of the samples for the test purpose and the remaining $80 \%$ for running the model. The results showed that there was no significant difference between Backward, Testing Backward and Training Backward models. The results from the latter method showed that the NDVI of the pixels could be estimated for $79 \%$ of the cases. It can be stated that the rest of NDVI values could be affected by other environmental parameters such as soil type and characteristics, topographical conditions, agronomical practices, plant diseases and other unknown factors. Finally, some maps were developed showing the potential wheat farming in the area according to the model results.

Keywords: NDVI, wheat, GIS, multi-regression model, MODIS.
\end{abstract}




\section{Introduction}

Sustainable irrigation and crop production is closely related to climate adaptability of crops. On the other hand vegetative vigor or "greenness" of wheat could be considered as an appropriate index to measure water deficiency, and also plant health, density and quality. This index can be addressed by NDVI (Normalized Difference Vegetation Index). Climate adaptability of crops is also essential for the maximum climatological potential of farming and food production [1]. Therefore, if a model could be developed a model to use spatial distribution of climatological parameters along with NDVI one could determine the potential area for planting a specific crop such as wheat.

Many researches have been done in different areas in different parts of the world in this field of study. Vento [2] used a GIS model to collect environmental, economical and agricultural data for an area located in Northern Italy and developed a model for yield production and making a decision support system for farm management. Wright et al. [3] also used a spatial analysis with Ikonos and Quickbird satellite images for wheat farms to investigate yield production under water deficiency conditions.

Wheat is an important and strategic cereal which covers most of the agricultural plantation areas in the world [8] and in Iran as well. Vegetative vigor or "greenness" could be considered as an index for wheat farm conditions. This index can be measured from satellite datas and processed into Normalized Difference Vegetation Index (NDVI) composites [4]. It is obvious that wheat production as well as other plants is influenced by climatological parameters. In this study we considered the most four important climatological parameters influencing wheat crop and used developed multi-regression analysis models to identify the potential areas which are climatologically suitable for wheat cultivation.

\section{Materials and methods}

Mashhad county was selected as the study area, which is located between 59.01 to 60.31 Longitude and 35.40 to 37.06 Latitude. The mean height of the area above sea level is 1812 meters with maximum of 3100 and minimum of 800 meters. This area is located in North East of Iran. Three farms were selected in Mashhad area, which cultivated to wheat during 2004 to 2005 growing seasons and their geographical location was determined by a GPS. Normalized Difference Vegetation Index (NDVI) was used to extract vegetation cover in the area from the satellite images. The index is defined as [5]:

$$
\mathrm{NDVI}=(\mathrm{NIR}-\mathrm{Red}) /(\mathrm{NIR}+\mathrm{Red})
$$

In which NIR is near infra red band and Red is red band of the images. Theoretically, the index value varies between -1 and $+1[5]$. The index value varies from 0.3 to 0.6 for dense vegetation cover [6].

MODIS (Moderate-resolution Imaging Spectroradiometer) images from Terra satellite were selected to calculate NDVI. "MODIS makes it possible for continuous monitoring (16 days returning period) of the environment by 
measuring atmospheric trace gases and aerosol density, and mapping the surface of clouds, land and sea in a variety of spectral ranges from the blue to the thermal infra-red (4 to 15 micrometers)" [7]. The Red band (0.62 to 0.67 micrometers) and NIR (0.841 to 0.876 micrometers) were selected to calculate NDVI using the above equation. The images were taken by the satellite in 49 and 289 Julian days in 2004. Figure 1 shows the calculated NDVI in a map for the area. ArcMap software was used to calculate NDVI.

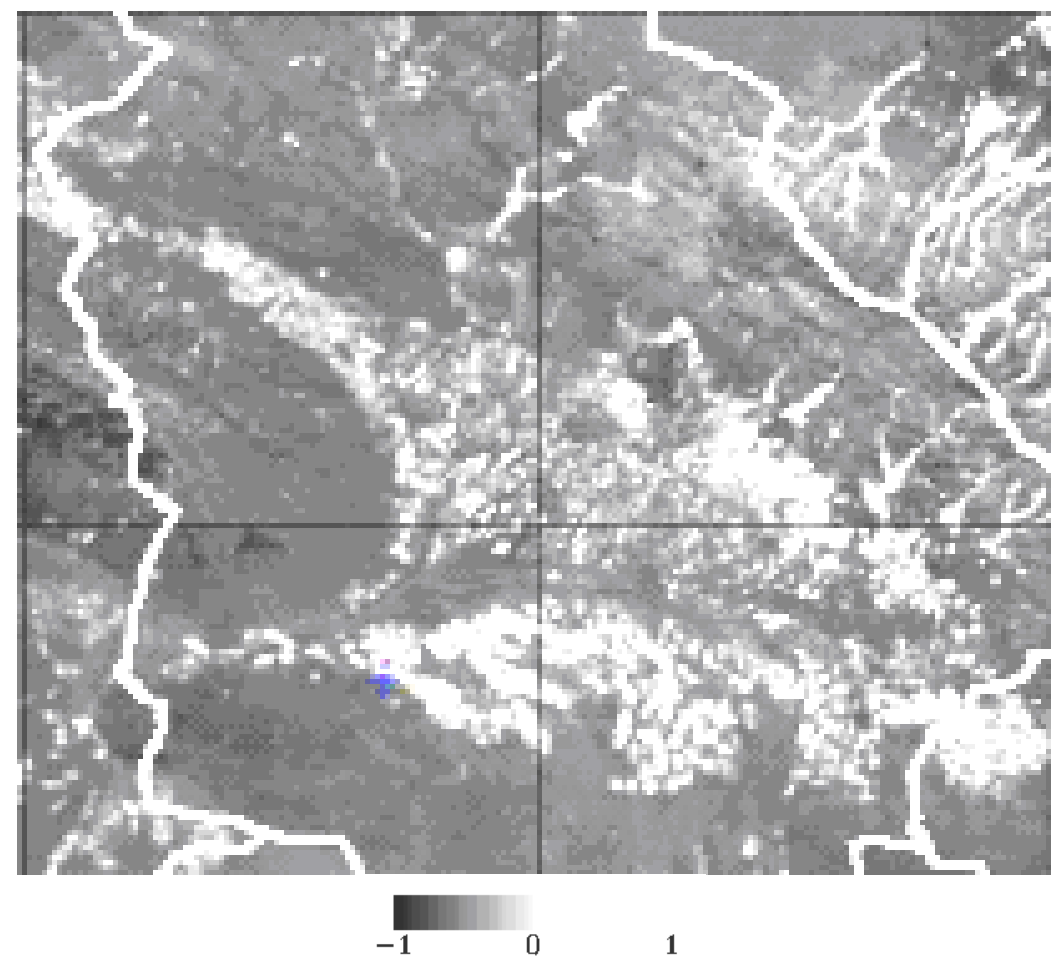

Figure 1: $\quad$ NDVI, calculated by using MODIS images for Mashhad area.

The image processing and also geo-processing procedures were performed as it was reported by Sanaeinejad and Shahtahmasebi [8]. Twelve locations were selected across the image to generalize the NDVI values which were derived for the reference farms. The locations were considered to match the following criteria if:

- They were uniformly distributed across the images and

- Their NDVI values were in the same range of the reference farms. 

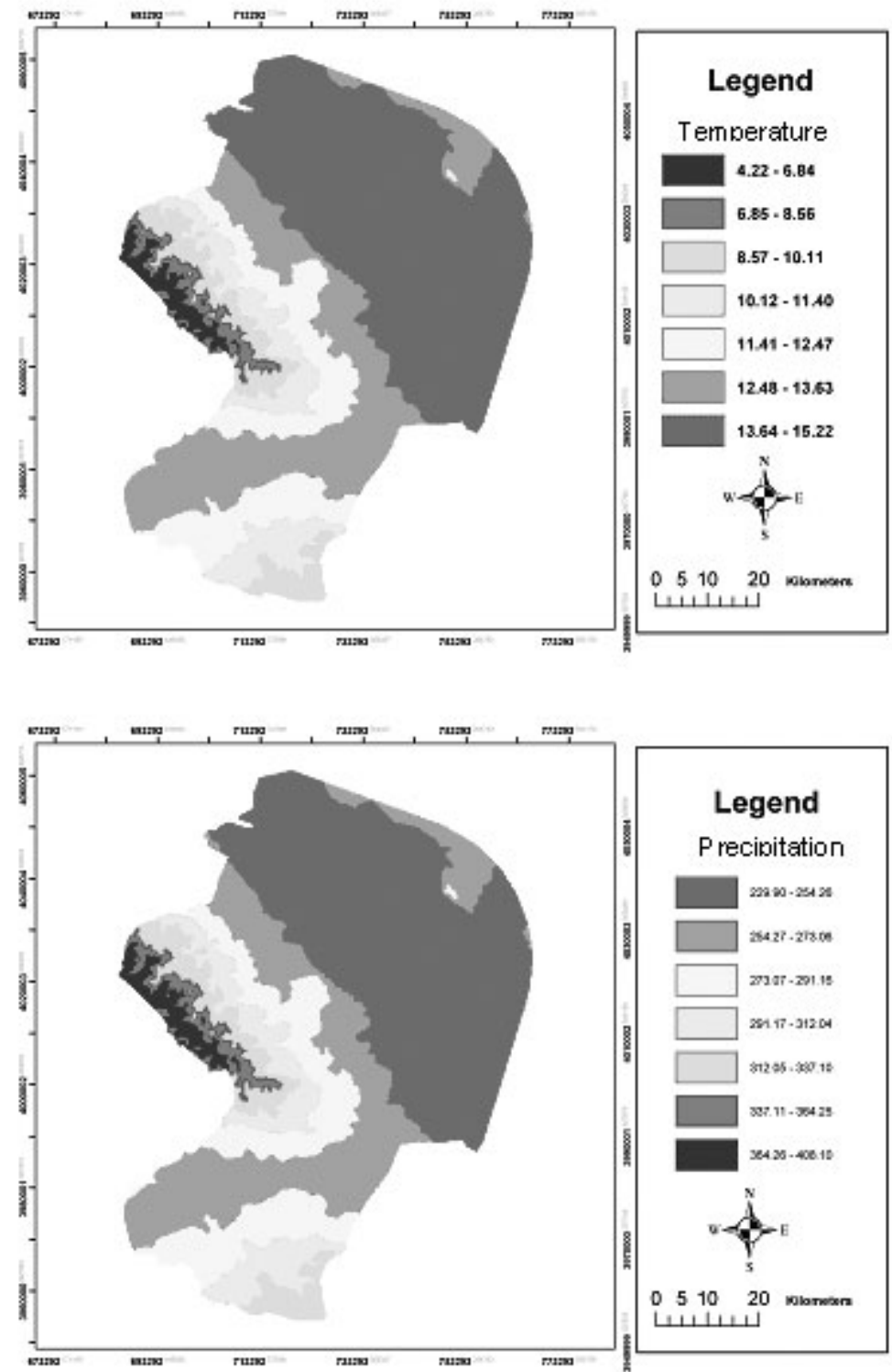

Figure 2: $\quad$ Spatial distribution maps of mean annual air temperature (top) and total Precipitation (bottom) in the study area.

Four climatological parameters including air temperature, precipitation, relative humidity and sunshine hours were considered and their relations with the calculated NDVI for each area were determined. The climatological data were collected from the nearest weather stations. The value of climatological 
parameters were determined by using some regression equations derived from the climatological data and elevation values of the area from a DEM (Digital Elevation Model). Fig. 1 shows spatial distribution of air temperature and precipitation in the study area.

Stepwise regression method was used to perform regression analysis between the climatological parameters and NDVI values all over the study area.

Stepwise regression is a semi-automated process of building a model by successively adding or removing variables based solely on the t-statistics of their estimated coefficients. The three stepwise methods including Forward, Backward and Enter were examined in the statistical analysis and the following equations were derived for each method:

\section{Forward method}

$$
\mathrm{Y}=-5231.37+\left(9.321 \mathrm{X}_{1}\right)+\left(89.081 \mathrm{X}_{2}\right)+\left(53.725 \mathrm{X}_{3}\right)
$$

In which $\mathrm{y}$ is the wheat NDVI, $\mathrm{X}_{1}$ is sunshine hours, $\mathrm{X}_{2}$ is relative humidity and $\mathrm{X}_{3}$ is the mean air temperature.

\section{Backward method}

$$
\mathrm{Y}=37.8373+\left(84.77 \mathrm{X}_{1}\right)+\left(3.036 \mathrm{X}_{2}\right)
$$

In which $\mathrm{y}$ is the wheat NDVI, $\mathrm{X}_{1}$ is air the mean temperature and $\mathrm{X}_{2}$ is total annual precipitation.

\section{Enter method}

$$
\mathrm{Y}=-4182.75+(6.763 \mathrm{X} 1)+(68.093 \mathrm{X} 2)+(1.832 \mathrm{X} 3)+(56.608 \mathrm{X} 4)
$$

In which is the wheat NDVI, $X_{1}$ is the total sunshine hours, $X_{2}$ is the relative humidity, $\mathrm{X}_{3}$ is the total annual precipitation and $\mathrm{X}_{4}$ is the mean air temperature.

\section{The results}

The three statistical methods were used to model NDVI values over the study area based on the data derived from the reference wheat farms. The three statistical models were compared and it was concluded that Backward method had the highest correlation (0.78) with the NDVI values over the study area. Table (1) shows the comparing results.

The p-values from Wilkakson test showed that zero hypothesis for equality of the means were acceptable for Backward and Enter methods according to NDVI values, however, the best results were derived frrom Backward method. Therefore, backward method was selected for modeling wheat NDVI over the area using $80 \%$ of the collected data.

The results derived from the model were tested using the remaining $20 \%$ of the data. The correlation coefficient for training the model was 0.89 while for testing the results was 0.91 which shows a good correlation between real NDVI values derived from the images and the values calculated from the model.

Using the model, the NDVI for wheat crop was estimated over the area. Figure 3 shows the mapping of the results. Actually, this map shows the areas where in practice the climatological conditions are suitable for wheat cultivation. 
Table 1: The comparing results of correlation analysis for the three Backward, Enter and Stepwise methods.

\begin{tabular}{cccc}
\hline Model & $\mathrm{R}^{2}$ Adjusted & $\mathrm{R} 2$ & $\mathrm{p}$-value \\
\hline Forward & 0.047 & $5 \%$ & 0.001 \\
Enter & 0.36 & $38 \%$ & 0.229 \\
Backward & 0.78 & $79 \%$ & 0.389 \\
\hline
\end{tabular}

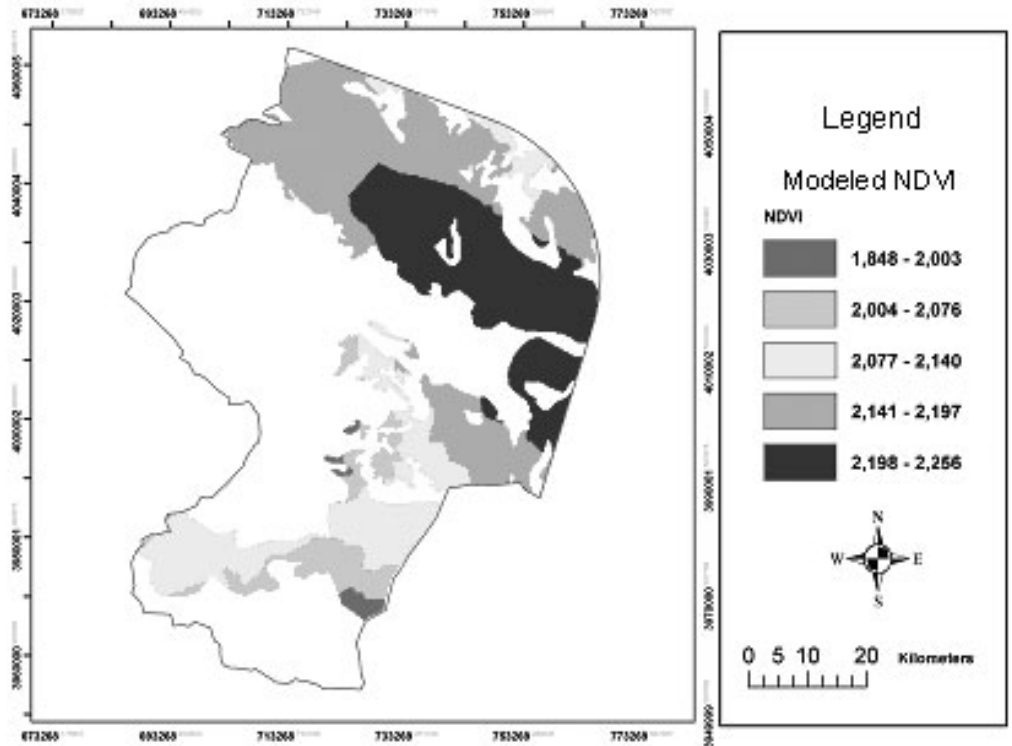

Figure 3: The map showing NDVI derived from the Backward model for Mashhad area.

\section{Conclusions}

This study showed that a multi-regression model (here Backward method) of climatological parameters with NDVI can be used to develop potentially suitable areas for wheat production. Since MODIS images are easily available, this method can be used to extend the results for remote areas all over the world for predicting the potentially suitable areas for wheat production and also for managing wheat fields under different climatic condition. In addition, the same analysis can be used to determine crop water needs for irrigation planning. 


\section{References}

[1] Ministry of Agriculture, http://www.agri-jahad.org/introduce.asp?page= importantplan.htm

[2] Vento, D.

[3] Wright, D. L., D. Ramsey, R. Baker, D. V. Rasmussen, 2003 “A Comparison of two Geospatial Technologies in Non-Uniform Wheat Fields: Yield Monitors and Remote Sensing ”. ASPRS 2003 Annual Conference Proceedings.

[4] FAOonline, 2002, http://www.fas.usda.gov/pecad2/highlights/2002/04/syria/

[5] Rouse, J. W., R. H. Haas, J. A. Schell and D. W. Deering, 1973. Monitoring vegetation Systems in the Great Plains with ERTS. Third ERTS Symposium, NASA SP - 351, vol. 1, pp. 309.

[6] Simpson J. and J. A. Stitt. 1998. Procedure for the detection and removal of clouds shadow from AVHRR data over land. IEEE Transactions on Geoscience and Remote Sensing, vol. 36, no 3, pp: 880-897.

[7] MODIS, 2005, http://eoweb.dlr.de:8080/short_guide/D-MODIS.html

[8] Sanaeinejad, S. H. and A. R. Shahtahmasebi, 2007, Estimating Wheat Planted area in North east of Iran by MODIS sensor, Proceedings, Map Asia 2007, Kualalumpor, Malaysia. 